REVIEW

\title{
Developments in modulating glycaemic response in starchy cereal foods
}

\author{
John R. N. Taylor, M. Naushad Emmambux and Johanita Kruger
}

Institute for Food, Nutrition and Well-being and Department of Food Science, University of Pretoria, South Africa

Correspondence: Professor John R. N. Taylor, Department of Food Science, University of Pretoria, Private Bag X20, Hatfield 0028, South Africa

E-mail: john.taylor@up.ac.za

Fax: $+27-12-4202839$

Running head: Glycaemic response in starchy cereal foods

Keywords: cereal foods, glycaemic index, obesity, resistant starch, whole grain 


\section{ABSTRACT}

One cause of obesity and related diseases like type- 2 diabetes is overconsumption of cereal foods with readily available carbohydrates, resulting in hyperglycaemia and ultimately insulin resistance. A strategy to combat this is to modulate glycaemic response through starchy cereal foods that have low glycaemic index (GI) because their starch is less available to digestion. In cereals, many factors can limit accessibility of amylase to the starch. Of these, intact pieces of endosperm, high levels of oat or barley $\beta$-glucan and high amylose starch are probably the most important. Starch accessibility in cereal foods is also greatly affected by processing. Heat-moisture thermal processing at low moisture above glass transition temperature, but below gelatinization temperature is probably the most effective processing technology to reduce starch availability. Formation of starch-lipid complexes also appears promising. Whole grain (milled whole kernel) cereal foods are intrinsically low GI but may have a long-term role in preventing obesity and type 2 diabetes through their phytochemicals, particularly polyphenols. A novel approach is to structure starchy cereal foods to deliver their carbohydrate at the distal end of the gastrointestinal tract to trigger the ileal and colonic brakes feedback systems so as to enhance satiety and hence decrease energy intake. 


\section{Introduction}

The world is facing a pandemic of obesity-related diseases, in particular type 2 diabetes and cardiovascular diseases. For example, in the USA some $34.9 \%$ of adults are obese [1]. The prevalence of diabetes, hypertension and dyslipidaemia among US adults is approx. $18.5 \%$, $35.7 \%$ and $49.7 \%$ in those who are obese compared to $5.4 \%, 19.8 \%$ and $28.6 \%$ in those of normal weight [2]. Obesity rates in low and middle income countries have also been growing rapidly, on average 0.7 percentage points per year [3]. In 2011, on average $19 \%$ of rural women and $37 \%$ of urban women were overweight or obese in these countries [3].

One widely accepted thesis as to why obesity is increasing rapidly across the world is that there has been a huge increase in passive consumption of "high energy" foods [3, 4]. It has been blamed on changes in the global food system due to the rise of "big food" companies, which has facilitated the wide availability of more processed, affordable, and effectively marketed food [3-5]. US food consumption data supports this as it indicates that cereal-based foods contribute some 19\% of the calorific intake of Americans, with the major cereal food items being refined flour products, including cakes, cookies (biscuits), quick breads (muffins), pastries, pies, crackers and pretzels [6]. Carbohydrates are the major source of calories in these foods, followed by fats and proteins [6].

The carbohydrates in cereal grains comprise: starch, non-starch polysaccharides including cellulose, pentosans such as arabinoxylans and $\beta$-glucans, and small amounts of simple sugars and oligosaccharides [7]. Quantitatively, starch is by far the largest component. Carbohydrates can be classified as to whether they are blood glucose raising after digestion, referred to as glycaemic carbohydrates, or non-glycaemic [8]. The non-starch 
polysaccharides, the cell wall materials in cereal foods are non-glycaemic. Simple sugars, oligosaccharides and dextrins are glycaemic and the starch in cereal foods is predominantly glycaemic. However, the extent to which the starch is available to digestion in cereal grains and foods is dependent on many intrinsic and extrinsic factors $[9,10]$.

An area of great current interest is to modulate (limit) the availability of the energy supplying macronutrients in cereal foods to digestion and availability, in particular the starch $[9,11]$. The major aim is to reduce calorific intake and hence reduce the incidence of obesity, which should in turn reduce the incidence of obesity-related diseases. Also, the consumption of low glycaemic index (low GI) cereal foods has been more directly associated with prevention and alleviation of type 2 diabetes [12].

This review firstly briefly examines how starch is digested in cereal foods and the importance of the degree and rate of digestion, and measurement of the resulting glycaemic response. It then focuses on how cereal grain structure and chemical composition can influence the availability of the starch to digestion and on research into the effects of processing cereal foods on limiting starch availability. In parallel, the impacts of these cereal grain factors, processing and modifications on glycaemic response in vitro and in human studies are evaluated. The review concludes with some remarks on future avenues to curb obesity and prevent type 2 diabetes with respect to starchy cereal foods. 


\section{Starch digestion and glycaemic response}

\subsection{Starch digestion in the gastrointestinal tract}

As indicated, starch from cereal grains still makes up the bulk of glycaemic carbohydrates consumed [13]. Cereal starch is digested throughout the gastrointestinal tract. In the mouth, the salivary glands produce lingual $\alpha$-amylase [14]. It is the most abundant protein in the saliva and the most important enzyme involved in the initial digestion of starch [15]. On average, only about $5 \%$ of starch is digested in the mouth [13]. However, it has been found that $\alpha$-amylase can play a major role in the digestion of cereal foods, hydrolysing $50 \%$ of bread starch and $25 \%$ of pasta starch during the short chewing time (19-27 s) [16]. Other research has shown that high endogenous salivary $\alpha$-amylase activity is associated with improved glycaemic homeostasis [17]. Individuals with high $\alpha$-amylase concentrations in their saliva may be better adapted to consume starches, whereas individuals with low $\alpha$ amylase concentrations may be at greater risk for insulin resistance if chronically consuming starch-rich diets [17]. Interestingly, a significant association of a multi-allelic copy number variant encompassing the ligual amylase gene (AMY1) with body mass index (BMI) and obesity has recently been identified [18]. Increased AMY1 copy number was positively associated with both amylase gene expression and serum enzyme levels, whereas reduced AMY1 copy number was associated with increased BMI and obesity risk.

While the low $\mathrm{pH}$ environment of the stomach reduces $\alpha$-amylase activity by approximately $70 \%$, starch hydrolysis still continues and some $15 \%$ of the total starch (10\% digestion in stomach plus $5 \%$ in the mouth) in a meal is digested by the lingual $\alpha$-amylase [13]. Gastric emptying is a major determinant of starch digestion. Slower gastric emptying reduces the mass transfer of chyme (and starch) into the small intestine [19]. In the small intestine, pancreatic $\alpha$-amylase continues the starch hydrolysis. Although $\alpha$-amylase rapidly hydrolyses 
starch molecules to small oligosaccharides and dextrins, it does not produce much glucose [13]. In the small intestine enzymes including $\alpha$-limit dextrinase, glucoamylase, maltase, sucrose and isomaltase, are responsible for the breakdown of the dextrins and oligosaccharides into glucose [13-15]. Glucose can be absorbed by the epithelial cells throughout the small intestine. The resulting increase in blood glucose causes the release of insulin, which stimulates glucose transport into various cells 20]. After consuming starch, the rate and quantity of glucose absorption together with the insulin response over time (normally 2 hours) is regarded as the postprandial glycaemic response [21]. According to the International Diabetes Federation, postprandial hyperglycaemia is defined as a plasma glucose level $>7.8 \mathrm{mmol} / \mathrm{l}(140 \mathrm{mg} / \mathrm{dl})$ two hours after the ingestion of food [21].

Postprandial hyperglycaemia has been implicated in the development of chronic metabolic diseases like obesity, type 2 diabetes and cardiovascular disease [21, 22]. A number of studies have confirmed that hyperglycaemia (also referred as glucose toxicity) can also lead to insulin resistance, but the precise mechanism/s of action is not known [20].

\subsection{Measurement of carbohydrate availability in foods}

The glycaemic index (GI) of a food, first defined by Jenkins et al. [23], is widely used to estimate in vitro or express in vivo the effect of available carbohydrates in a food on the glycaemic response. The GI represents a measure of the average concentration of glucose in the blood following consumption of a test food, ingredient or meal (usually containing $50 \mathrm{~g}$ available carbohydrate), over a set period of time (usually 2 hours), and is expressed relative to a standard or reference food, normally glucose or white bread [24]. Despite its very wide use, the GI assay has considerable limitations. GI values for the same foods from different 
laboratories can differ, often as a result of intra- and inter-subject variations [25]. Also, GI does not take into account the insulin response [25]. Further, it has also been found that GI does not seem to show dose response effects in respect of health factors [26].

Concerning the food, GI does not take into account that serving sizes differ for different food products [25]. Glycaemic load, however, relates the GI to the amount of available carbohydrates in a serving or amount consumed, and thus refers to the total exposure to postprandial glycaemia over a specified time period [24]. GL can thus be used as an indicator of insulin demand [24].

The different starch fractions in a cereal grain or meal, usually measured by in vitro assay, are commonly categorised as rapidly digestible starch (RDS), slowly digestible starch (SDS) and resistant starch (RS) [27]. RS is starch that is resistant to enzymic hydrolysis in the small intestine [28]. Since starch digestion follows a first-order kinetic reaction, the division of the starch into RDS and SDS fractions on the basis of a slowing in the digestion rate as the reaction proceeds has been criticised. It has been found that the starch digestion rate naturally becomes slower because the concentration of substrate decreases [29]. The logarithm of slope (LOS) has been applied to starch digestibility data curves to identify and quantify nutritionally important starch fraction; rapid and single/slower digestible starch phases $[29,30]$. A major benefit of the LOS approach is that the contribution of each phase to total starch breakdown can be calculated [30].

In general, cereal starch is rapidly digestible, and the resulting glucose is absorbed promptly in the upper section of the small intestine. This, together with the high starch content (and thus GL) of cereals, has great potential to result in an excessive postprandial glycaemic 
response [26]. Consumption of high GI and GL cereal foods by individuals who are insulin resistant can result in postprandial hyperglycaemia [21]. However, contrary to common belief, low GI foods are not always slow digesting with a modulated glycaemic response (Fig. 1B), for example when the rapidly digestible starch is replaced by added protein or insoluble dietary fibre [27].Conversely, slowly digestible starchy cereal foods with a modulated blood glucose curve (Fig. 1C), such as sorghum-based foods (see under 3.4), could be calculated to have a relatively high GI [27]. Accordingly, an extended GI (EGI) has been proposed, which can be used to specify the extent of glucose release over a prolonged time period [27]. Although SDS is a major topic of research, its exact locations of digestion and absorption in the small intestine is not known [13]. Nevertheless, the resulting modulated postprandial glycaemic response of SDS and the slow energy release have been shown to contribute to increased mental performance and have been associated with reduced risk of diabetes and cardiovascular disease [31,32].

Resistant starch in cereal foods passes through the small intestine undigested and undergoes microbial fermentation in the colon [14]. The products of RS fermentation in the colon include short chain fatty acids, which promote colonic health. There is evidence that RS in the diet aids in blood glucose regulation and promotes growth of beneficial bacteria in the colon and that consumption of RS may even reduce the risk of colonic cancer [14].

A systematic review and meta-analysis of published research on the relationship between dietary glycaemic properties and health outcomes concluded that reductions in GI and so GL do in fact improve glycaemic control [26]. However, importantly, it was also observed that for optimal diabetes control, the evidence points toward the need for foods that have both a low glycaemic impact (independently of fat intake) and foods that are high in unavailable 


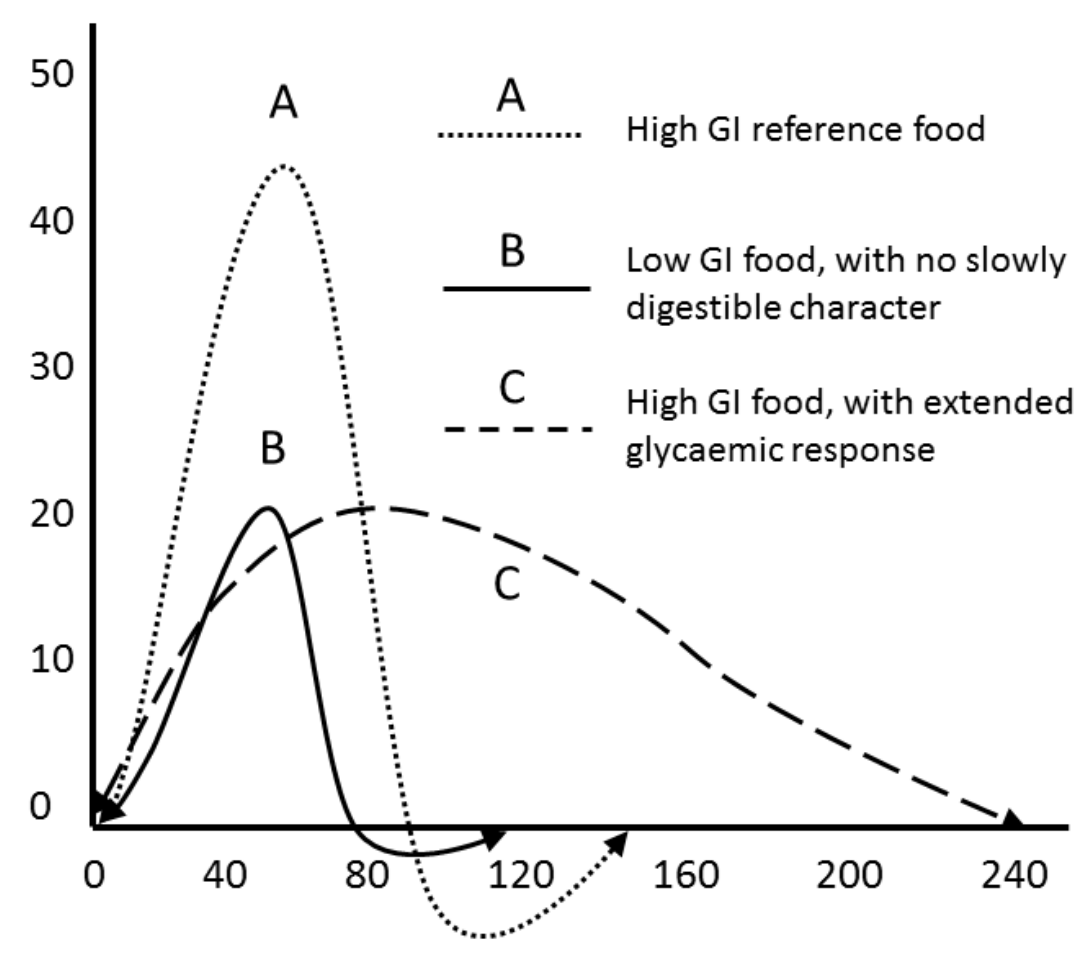

Figure 1. Theoretical glycaemic response curves of cereal grains and/foods. Adapted from [13,27]. 
carbohydrates. [26]. Cereal foods with low GI and GL would very often also be high in unavailable carbohydrates such as RS and fibre, as is discussed below.

\section{Influence of cereal grain structure and composition on starch digestion}

\subsection{Whole grain}

Of particular importance with respect to modulating glycaemic response when cereal foods are consumed is RS type 1 - physically inaccessible starch [33]. In cereals, starch that is isolated in intact endosperm cells is the most common RS1 form. Intact cells limit amylase enzyme access to the granules. The most extreme form is "whole grains", or far more correctly, intact grains. In multigrain breads, for example, the structure of the intact grain is an important factor determining amylase availability and hence metabolic response [34]. The subject of whole grain cereal foods is, however, very vexed as the term "whole” grain is used to describe both intact grains (kernels/caryopses) and ground grain comprising all the anatomical components of the caryopsis. AACC International define whole grains as "consisting of the intact, ground, cracked or flaked caryopsis, whose principal anatomical components — the starchy endosperm, germ, and bran-are present in the same relative proportions as they exist in the intact caryopsis” (www.aaccnet.org).

Not surprisingly, there is considerable confusion concerning the influence of "whole grain" on the rate of starch digestion. The various forms of whole grains listed by AACC International differ substantially in terms of their GI when in the form of a food such as bread (Table 1). Notably, bread made from whole-meal (essentially whole wheat grains ground 
Table 1. Measured glycaemic indexes of various types of wheat bread. Data from [62].

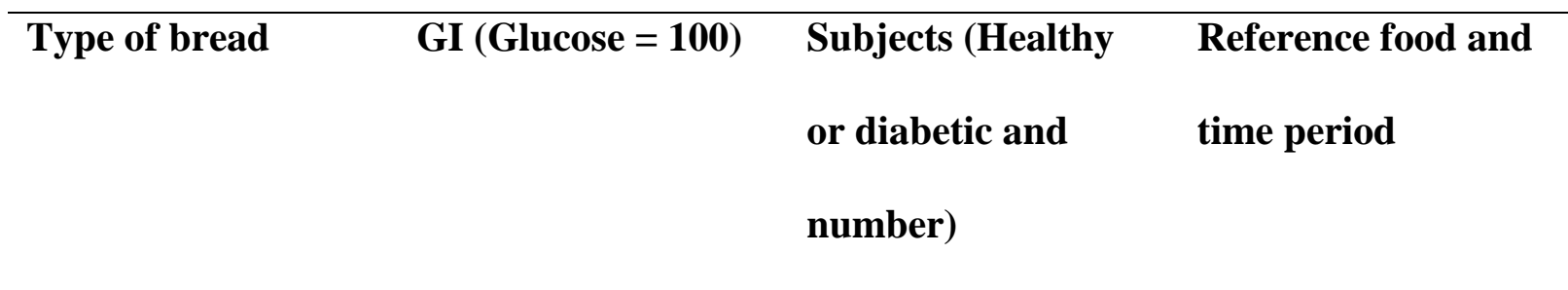

\section{White wheat flour}

bread

Canada

$69 \pm 5$

Healthy, 10

Glucose, 2 h

Australia

70

Healthy, 10

Bread, 2 h

South Africa

$71 \pm 7$

Healthy, 7

Glucose, 2 h

\section{Breads containing}

intact or pieces of

wheat grains

$80 \%$ intact wheat

52

Healthy, 10

Bread, 2 h

kernels-20\% white

wheat flour (Sweden)

50\% cracked kernels 58

Type 2, 6

Bread, 3 h

(Canada)

50\% kibbled

43

Healthy, 8

Bread, 2 h

(crushed) wheat grain

(Australia)

Whole-meal flour

Canada

$72 \pm 6$

Healthy, 10

Glucose, 2 h

Australia

$77 \pm 9$

Healthy, 8

Glucose, 2 h

South Africa

$75 \pm 9$

Healthy, 8

Glucose, 2 h

Mixed grain breads 
Australia

$34 \pm 4$

Australia

$45 \pm 12$

White bread

containing added

fibre

High fibre (Canada) 67

High fibre (Canada) 69

Psyllium fibre

41

(Mexico)

Psyllium fibre

65

(Mexico)

Oat bran $-50 \%$

44

(Australia)

Oat bran- $45 \%$

50
Healthy 10-12

Healthy, 10
Bread, 2 h

Glucose, 2 h
Type 1 and 2, $13 \quad$ Bread, $3 \mathrm{~h}$

Type 1 and 2, $12 \quad$ Bread, $3 \mathrm{~h}$

Type 2, 12

Bread, 3 h

Healthy, 10

Bread, 3 h

Healthy, 8

Bread, 2 h

(Sweden)
Healthy, 10

Bread, $1.5 \mathrm{~h}$ 
into a flour) has the same GI has bread made from white flour (essentially finely milled starchy endosperm). In fact, most "whole grain” cereal products including breads and breakfast cereals and other processed foods have a GI of over 70 [35]. The reasons that bran does not reduce GI and starch digestibility are complex. They may be related to the necessity to prepare the products with higher levels of water because of bran water absorption, which may increase starch water absorption during baking [36]. Thus, the suggestion that foods make from whole grain cereals, e.g. sorghum and pearl millet, have low GI due to their apparently high insoluble dietary fibre content [37], should be treated with caution.

\subsection{Fibre}

The effects of adding fibre on the GI of cereal foods such as bread is not clear, as both the nature of the fibre (insoluble and soluble) [38] and health status of the consumer (healthy or diabetic) seem to play a role (Table 1). Concerning cereal fibre type, uniquely, the starchy endosperm cell walls of oats and barley, confusingly referred to as oat or barley bran [39], predominantly comprise mixed linkage $\beta$-glucans $((1 \rightarrow 3,1 \rightarrow 4)-\beta$-D-glucans $)$, and are form of soluble fibre [40]. These $\beta$-glucans have been the subject of intense research in respect of their serum cholesterol and glycaemic response attenuating properties [41]. With breads made with wheat flour, barley flour and barley $\beta$-glucans, there was a linear dose-related decrease in glycaemic response with bread $\beta$-glucan content [42]. The best mechanistic theory is that the reduction in glycaemic response is related to high viscosity imparted by the $\beta$-glucans, similar to guar gum [41]. In vitro assay and clinical trial indicate that this property of $\beta$-glucan limits starch digestion [43]. However, is unclear whether limited starch digestion is due to the $\beta$-glucans' high affinity for water reducing hydration of the starch granules or whether the highly concentrated $\beta$-glucan phase in the food inhibits amylase accessibility 
[43]. Modification of other cereal non-starch polysaccharides may make them also behave like $\beta$-glucan. Increasing wheat arabinoxylan (wheat endosperm cell wall non-starch polysaccharides [40] solubility in wholemeal wheat bread by sourdough fermentation decreased postprandial glucose and insulin response [44].

However, of particular note is the observation that rolled oats, the richest natural food source of $\beta$-glucan, 4\% dry basis, is not a low GI food [41]. The above described findings of lowering glycaemic response were achieved by adding additional $\beta$-glucan to foods. Even doing this does not necessarily lead to a positive outcome. In a study of the effects of an energy restricted diet on weight loss in mildly overweight women, supplementation with $\beta$ glucan did not enhance weight loss [45]. Nevertheless, a metanalysis of data from human studies involving consumption of oat and barley containing products indicated that consumption of intact grain products and of processed grain products containing at least $4 \mathrm{~g}$ $\beta$-glucan and 30-80 g available carbohydrate can significantly reduce postprandial blood glucose [46].

\subsection{Intact grains}

Concerning cereal foods containing intact cellular tissue, as opposed to being made solely from flour, breads made white flour plus intact, or crushed wheat grains, have significantly lower GIs (Table 1). Similarly, traditional African maize porridge has a low estimated GI, in part because much of the starch is isolated in intact cells [47]. Starch digestion is directly related the size of the particles of cereal grain. For example, with sorghum in vitro starch digestion by $\alpha$-amylase was found to proceed by diffusion based on an inverse square dependence on average particle size, over the approx. range of 120-560 $\mu \mathrm{m}$ investigated [48]. 
Even the smallest particle should contain some intact cells, since starchy endosperm cells in sorghum and wheat vary between approx. 60-150 $\mu \mathrm{m}$ across [49,50].

The nature of the cell walls in cereal particles does not seem to impact strongly on starch digestion. A comparison between the rates of starch digestion of barley and sorghum grain revealed that digestion rate was dependent on particle size in both cereals and that the rate of digestion was considerably slower with sorghum [51], despite the $\beta$-glucans in barley.

\subsection{Endosperm type and endosperm protein}

Some cereal grains, notably maize and sorghum, have two types of starchy endosperm, a dense outer corneous (vitreous) endosperm where the starch granules are tightly embedded and a much less dense inner, floury endosperm where the starch granules are loosely packed [52]. The relative proportion of the two endosperm types is genetically controlled [53] and influenced by environment. It has been well described in in vitro studies and animal feeding trials that the rate of starch digestion in maize [47,54] and sorghum [55] is inversely related to kernel corneousness.

With sorghum, there is strong evidence that a disulphide bond cross-linked matrix of kafirin prolamin proteins and other storage proteins in the corneous endosperm limits starch digestion, particularly when the grain is subject to wet cooking [55-59]. The probable mechanism is through the protein matrix limiting starch granule expansion during cooking [59]. Despite this, it is not clear cut as to whether sorghum is low GI. Even when the effects of sorghum products on GI measured in human subjects were compared directly with the same products made from wheat, one study showed no difference [60] and another that the 
sorghum products had lower GI [61]. There were, however, important differences in methodology in respect of whether the subjects were healthy or had non-insulin dependent diabetes and with respect to whether the bran content of sorghum and wheat food products were the same.

Wheat pasta is well known as a low GI food, and typically has a GI of $<50$ [62]. The reason is, however, not known and numerous theories have been proposed to explain the slow hydrolysis of its starch [63]. At least two theories concern the role of the gluten protein matrix. Thermally induced cross-linking of the gluten during pasta drying could tightly encapsulate the starch granules, limiting their water absorption during cooking [64]. Alternatively, the complex gluten network could result in a tortuous path for amylase accessibility [65].

\subsection{Starch}

The size and nature of the starch granules differ between cereal species. Wheat, barley, rye and triticale have two types of starch granules, large lenticular shaped A granules and smaller spherical B granules [66]. Below gelatinisation temperature, small granules in wheat, barley, triticale and maize were initially digested more rapidly by $\alpha$-amylase $[67,68]$. However, over time the rate of digestion of larger granules became more rapid. In certain cereal species, notably rice, teff and finger millet, some starch granules are compound, comprising a large structure of tightly packed small granules $[69,70]$. With native (raw) compound granules, amylolysis is may be restricted due reduced capacity of the amylases to bind to the granule surface [66]. However, it is doubtful whether the factors of starch granule size or compound granules have a significant impact on the GI of cereal foods when digested by humans as the 
starch has normally been gelatinised, i.e. in an amorphous (not semi-crystalline) state [71], and it is present in a food matrix.

The most important intrinsic starch factor that limits hydrolysis is the high amylose trait. An in vitro study showed that below gelatinisation temperature, high amylose maize starch (69.7\% amylose) was hardly hydrolysed $(<10 \%)$ over 72 hours, whereas normal maize starch was $>90 \%$ hydrolysed [68]. Human studies have shown that consumption of diets containing added high amylose starch modulates glycaemic response [72,73]. In a study with healthy subjects, inclusion of high amylose maize starch in bread reduced its GI to a similar level as spaghetti [73]. Promising results have also been found with newly developed high amylose rice using a rat animal model [74].

\subsection{Antinutrients}

Antinutrients in cereals can limit starch hydrolysis. Probably the most important are the polyphenolic condensed tannins (proanthocyanidins and procyanidins), located in the testa

(inner bran layer) of tannin-type sorghum and finger millet varieties [75]. However, research findings as to whether such tannins inhibit starch hydrolysis in foods from these grains are contradictory. With porridges made from sorghum endosperm, bran [76] and bran extracts [77] from tannin sorghum decreased in vitro starch digestibility and estimated GI, and increased RS. However, other work has shown that with cooked whole grain sorghum flours there was no correlation between tannin content, nor tannin molecular weight with RDS, SDS or RS [78]. This is somewhat surprising since it is well established that sorghum tannins inactivate amylases [79-81]. Also, they have been shown to bind strong strongly to starch, especially strongly with amylose, and reduce its digestion [82]. 
Concerning the possible effects of non-tannin polyphenols, a study with human subjects where purple (anthocyanin-rich) wheat bran was added to wheat bread did not reveal any difference in GI or starch digestion to bread with normal wheat bran added [83]. Further, the starch digestion rate of both bran-enriched breads was considerably higher than that of pasta with added normal wheat bran [83].

Phytate, the primary storage form of phosphate in grains and a chelator of essential minerals in foods [84], located in the aleurone and germ of cereals [85], can reduce blood glucose response in human subjects [86]. Several mechanisms of action of phytate have been proposed, including direct binding with the starch by hydrogen bonding, binding to proteins associated with the starch and possibly complexing of $\mathrm{Ca}^{2+}$ ions to inhibit $\alpha$-amylase [84].

\section{Influence of cereal food processing technologies on starch digestion}

Cereal grains and flours are not consumed raw but are generally thermally processed into foods such as porridge, bread, ready-to-eat breakfast cereals and fermented foods. It is well known that starch digestibility and GI increase from raw to processed foods. This is because native starch exists as a semi-crystalline structure and becomes gelatinised and pastes to produce an amorphous material that can be rapidly digested by the human salivary $\alpha$-amylase [87]. 


\subsection{Thermal processing - high moisture}

Heat processing technologies affect the rate of starch digestibility and can modulate GI [88]. Wet heat processing (cooking in excess moisture) such as boiling and pressure cooking increases the GI of cereal foods by reducing the levels of SDS and increasing starch digestibility $[89,90]$. However, one needs to be careful when assessing the effect of wet heat processing, as post-processing effects such as cooling can promote retrogradation to form RS type 3 (retrograded starch) [11] and this can reduce the food's GI [91]. Wet heat processing has been found to increase RS as well as reduce RS in various cereal foods and this was largely attributed to differences in methods of RS assay [11]. Nonetheless, changes in RS after heat processing are a consequence of the cooling conditions, and subsequent reheating and cooling cycles [92].

\subsection{Thermal processing - low moisture}

Heat processing under low moisture content can produce low GI or high GI cereal foods, depending on the mechanical energy applied. Biscuits (cookies) are low moisture short baking cereal products with low mechanical energy applied during dough making. Comparison of the GIs of several cereal products revealed that a plain biscuit had an estimated GI of 47, considerably lower than that of an extruded breakfast cereal, GI of 65 [93]. The authors also showed that the biscuits taken at breakfast contained SDS to modulate the glucose availability for the first part of the morning. Similarly, sweet plain biscuits had GI of 40-50 [94]. It was suggested that high RS in the biscuits was as a result of limited gelatinisation due to the low moisture of the biscuit dough, more sugar bound water and short baking time. These authors further found that were negative correlations between both fat and protein content and GI and suggested that these macronutrients can reduce enzyme accessibility to the starch [94]. 
Extrusion cooking is a low moisture, short time heat processing under shear and pressure. The mechanical energy input in addition to the thermal energy under pressure can depolymerise starches to low molecular weight dextrins. For example, extrusion reduced the amount of RS in rice cultivars of different amylose content and increased GI [91]. This resulted in formation of high GI products as their starches were rapidly digestible. Similarly, extrusion followed by flaking of both barley and oats resulted in products of similar GI to white bread [95]. In contrast, micronisation (a short heat processing technology with infrared heating) produced barley and oat products of lower GI, 66 [95]. It was suggested that extrusion followed by flaking gave smaller and uniform particle sizes during mastication compared to a heterogeneous and larger particle size with micronisation.

Microwave cooking can increase the starch digestibility of cereal foods such as baked poundtype cake [96] and freshly cooked rice [97] when compared to conventional baking and cooking. This effect of microwave cooking is suggested to be due to a greater heat penetration of the microwave energy. However, after storage the microwave cooked rice and the pound cake both had a lower starch digestibility as a result of increased RS3 compared to freshly baked products [96,97].

Heat-moisture treatment is another type of low moisture-high temperature heat processing. These are low moisture $(<35 \%)$ heat processing above the glass transition temperature, but generally below the gelatinisation temperature [32]. Heat-moisture treatments do not alter the starch granular structure, but affect the molecular structure by increasing the crystallinity and packing of molecules in the granule [98]. This low moisture heat treatment has been shown to decrease starch digestibility in germinated brown rice [99] and foxtail millet flour [100]. 


\subsection{Non-thermal processing technologies}

Non-thermal energy processing such as gamma-irradiation can increase or decrease GI depending on dose. A reduction in in vitro starch digestibility of raw and cooked maize-bean composite flours was found when the raw flour was subjected to gamma-irradiation doses $>2.5 \mathrm{kGy}$, but the digestibility was higher at $2.5 \mathrm{kGy}$ [101]. Similarly, a decrease in molecular weight of normal and waxy maize starches was found from 5-20 kGy, but the RS increased [102]. The increase in RS can be due transglucosidation [103], which causes the formation new bonds without disrupting the starch granular structure.

Sourdough fermentation (mixed bacteria and yeast fermentation) is used to produce many traditional cereal food products [104,105]. It was found that the in vivo GI of sourdough wheat bread was approx. 54 compared to about 72 for regular wheat bread [106]. Similarly, barley bread containing lactic acid had reduced GI compared to bread without lactic acid [107]. The lactic acid was added to simulate a sourdough fermentation product. Moreover, healthy individuals who ate bread containing lactic acid still had a lower glucose response after eating a high GI lunch [107]. It has been suggested that lactic acid formed during sourdough fermentation lowers the rate of starch hydrolysis, and propionic and acetic acid formed lowers gastric emptying rate [106]. It has also been proposed that sourdough fermentation increases interaction between starch and proteins [108], and, as mentioned, can increase soluble arabinoxylans [44]. 


\subsection{Formation of starch-lipid complexes}

Lipids, more specifically fatty acids, can interact with starches to form amylose-lipid complexes [109] and this can be enhanced during wet heat processing [110]. The molecular structure and the semi-crystalline nature of amylose-lipid complexes can reduce starch digestibility. When various fatty acids were allowed to interact with starches during processing, they reduced the enzymatic hydrolysis of amylose [111]. It has been found that stearic acid can reduce and slow the hydrolysis of maize and teff starches by thermostable $\alpha$ amylase when starch is cooked with the fatty acid [110] (Fig. 2). This is shown by a slower decrease in viscosity during hydrolysis and a higher final viscosity of the starches complexed with fatty acids (Fig. 2). These starches were pasted for 30 and $120 \mathrm{~min}$. The reduction in hydrolysis increased with increase in pasting time. It was suggested that the amorphous type I amylose-lipid complexes formed during short pasting are more prone to hydrolysis compared to semi-crystalline type II amylose-lipid complexes formed during extended pasting. It is also suggested that as stearic acid increased the paste viscosity this may also play a role limiting starch digestion. Notwithstanding the effect of amylose-lipid complexes on starch digestibility, most research has been done on formation of starch-lipid complexes of starches rather than in cereal-based foods. In fact, a considerable decrease in GI of corn tortilla with addition of flax seed oil has been found [112]. Amylose-lipid complexes could well have been responsible, although these were not characterised.

\section{Conclusions and future directions}

Whole grain cereal foods made from flour are not per se low GI. Glycaemic response in cereal foods can, however, be modulated by rendering the starch physically or chemically less available to digestion. Foods containing intact pieces of cereal endosperm, high levels of 


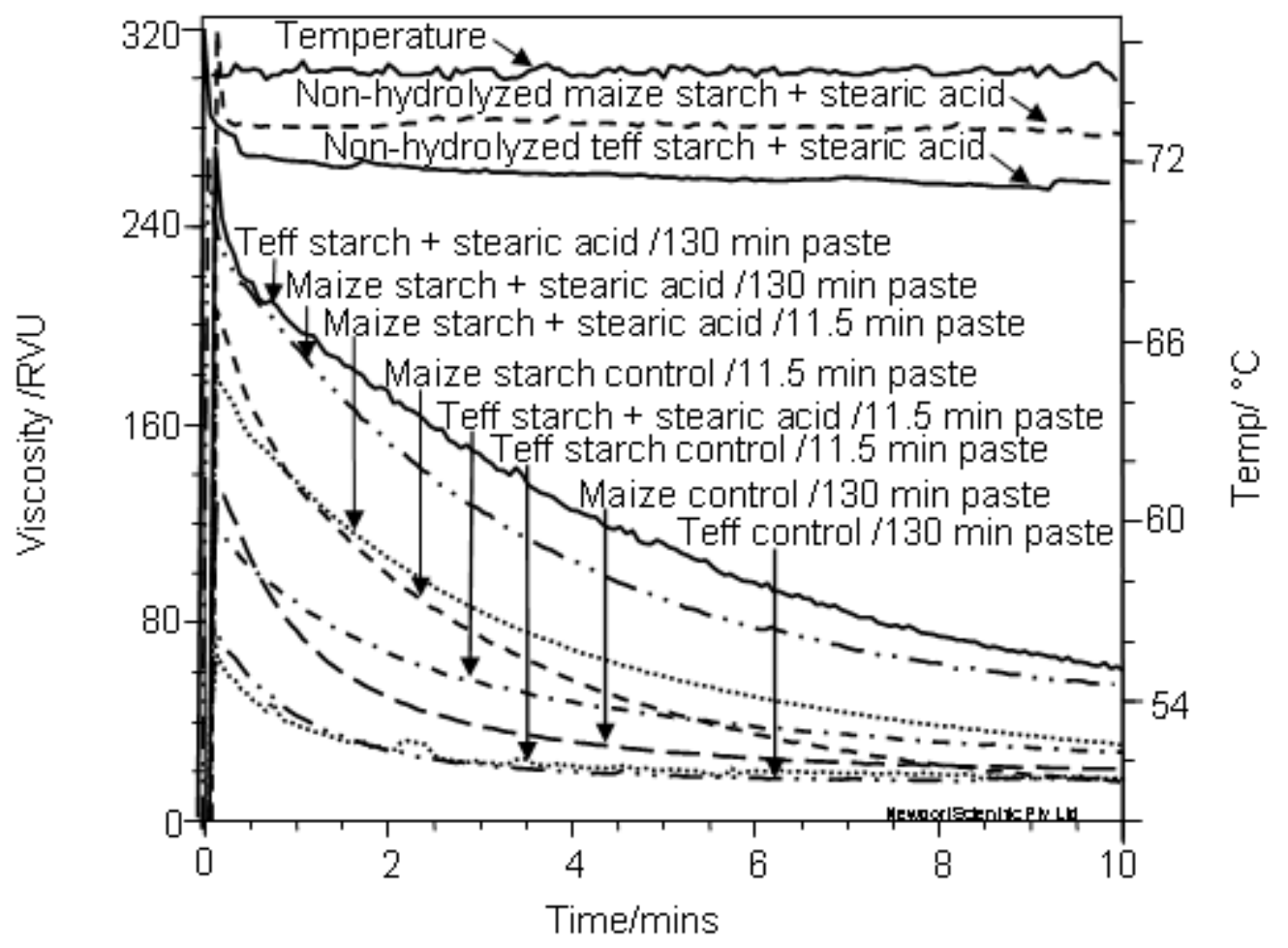

Figure 2. Effect of thermal stable alpha-amylase hydrolysis on viscosity of teff and maize starches pasted for 11.5 and 130 minutes at $90^{\circ} \mathrm{C}$ with or without added stearic acid $(1.5 \%$ with respect to starch). $\mathrm{R}$ eproduced with permission from [110]. 
oat or barley $\beta$-glucan and high amylose starch lower glycaemic response. Heat-moisture thermal processing is probably the most effective processing technology and formation of starch-lipid complexes appears promising. A general problem, however, is that many of the research findings are contradictory. There is a clear need for more rigorous research standards, for example uniform GI methodology and detailed physical and chemical characterisation of the cereal foods.

Even if whole grain cereal foods are not intrinsically GI, they may nevertheless have a longterm role in preventing obesity and type 2 diabetes through the action of the phytochemicals that are present $[113,114]$. Several mechanisms have been proposed that involve prevention of oxidative stress and low grade inflammation by phenolic compounds $[115,116]$.

Polyphenol-rich extracts have been shown to also inhibit glycogen synthesis in rats with drug-induced diabetes [117]. Magnesium, which is present in substantial amount in whole grain cereal foods (wholewheat bread $70 \mathrm{mg} / 100 \mathrm{~g}$ [118] may also have important actions. It has been shown to increase insulin secretion and blood glucose clearance in human subjects [113].

Perhaps the most intriguing obesity prevention research area are the "ileal and colonic brakes”. There is evidence that protecting normally digestible macronutrients, including starch, so that they reach the ileum, the most distal part of the small intestine, or the colon, triggers the physiological feedback loops referred to as the ileal and colonic brakes, which suppress hunger and food intake $[13,119]$. A recent clinical trial where subjects received ileal infusions of glucose has shown for the first time that carbohydrates delivered to ileum can enhance satiety and hence decrease energy intake [120]. If proven, starchy cereal foods could 
potentially be structured using some of the technologies described in this review so that their carbohydrate triggers these feedback systems.

\section{Conflict of interest statement}

JRNT and JK declare they have no conflicts of interest. MNE declares that he is in the process of protecting intellectual property in the area of starch-lipid modification.

\section{References}

[1] Ogden, C.L., Carroll, M.D., Kit, B.K., Flegal, K.M, Prevalence of childhood and adult obesity in the United States, 2011-2012. J. Am. Med. Assoc. 2014, 311, 806-814.

[2] Saydah, S., Bullard, K.M., Cheng, Y., Ali, M.K., Gregg, E.W. et al., Trends in cardiovascular disease risk factors by obesity levels in adults in the United States, NHANES 1999-2010. Obesity 2014, 22, 1888-1895.

[3] Popkin, B.M., Adair, L.S., Ng, S.W, Global nutrition transition and the pandemic of obesity in developing countries. Nutr. Rev. 2012, 70, 3-21.

[4] Swinburn, B.A., Sacks, G., Hall, K.D., McPherson, K., Finegood, D.T. et al., The global obesity pandemic: shaped by drivers of local environments. Lancet 2011, 378, 804-814. 
[5] Monteiro, C.A., Moubarac, J.-C., Cannon, G., Ng, S.W., Popkin, B, Review: Ultraprocessed products are becoming dominant in the global food system. Obesity Rev. 2013, 14 (Suppl.), 21-28.

[6] Huth, P.J., Fulgoni III, V.L., Keast, D.R., Park, K, Auestad, N, Major food sources of calories, added sugars, and saturated fat and their contribution to essential nutrient intakes in the U.S. diet: data from the national health and nutrition examination survey (2002-2006). Nutr. J. 2013, 12, 1-10.

[7] Chibber, R.N., Ganeshan, S. Båga, M., Khandelwal, R.L, in: Wrigley, C., Corke, H., Walker, C. E. (Eds.), Encyclopedia of Grain Science, vol. 1, Elsevier, Oxford, 2004, pp. 168179.

[8] Englyst, K.N., Englyst, H.N, Carbohydrate bioavailability. Brit. J. Nutr. 2005, 94, 1-11.

[9] Burton, P.M., Monro, J.A., Alvarez, L., Gallagher, E, Glycemic impact and health: New horizons in white bread formulations. Crit. Rev. Food Sci. Nutr. 2011, 51, 965-982.

[10] Marsh, K., Barclay, A., Colagiuri, S., Brand-Miller, J, Glycemic index and glycemic load of carbohydrates in the diabetes diet. Curr. Diab. Res. 2011, 11, 120-127.

[11] Alsaffar, A.A, Effect of food processing on the resistant starch content of cereals and cereal products - a review. Int. J. Food Sci. Technol. 2011, 46, 455-462. 
[12] Gil, A., Ortega, R.M., Maldonado, J, Wholegrain cereals and bread: a duet of the Mediterranean diet for the prevention of chronic diseases. Pub. Health. Nutr. 2011, 14, 23162322.

[13] Lee, B.H., Bello-Pérez, L.A., Lin, A.H.M., Kim, C.Y., Hamaker, B.R, Importance of location of digestion and colonic fermentation of starch related to its quality. Cereal Chem. 2013, 90, 335-343.

[14] Perera, A., Meda, V., Tyler, R.T, Resistant starch: A review of analytical protocols for determining resistant starch and of factors affecting the resistant starch content of foods. Food Res. Int. 2010, 43, 1959-1974.

[15] Ganong, W.F., Barrett, K.E., Review of Medical Physiology, vol. 22. McGraw-Hill Medical, New York, 2005.

[16] Morell, P., Hernando, I., Fiszman, S.M, Understanding the relevance of in-mouth food processing. A review of in vitro techniques. Trends Food Sci. Technol. 2014, 35, 18-31.

[17] Mandel, A.L., Breslin, P.A, High endogenous salivary amylase activity is associated with improved glycemic homeostasis following starch ingestion in adults. J. Nutr. 2012, 142, 853-858.

[18] Falchi, M., Moustafa, J. S. E. S., Takousis, P., Pesce, F., Bonnefond, A. et al., Low copy number of the salivary amylase gene predisposes to obesity. Nature Genetics, 2014, 46, 492497. 
[19] Parada, J., Aguilera, J.M, Review: starch matrices and the glycemic response. Food Sci. Technol. Int. 2011, 17, 187-204.

[20] Tomás, E., Lin, Y.S., Dagher, Z., Saha, A., Luo, Z. et al., Hyperglycemia and insulin resistance: possible mechanisms. Annals New York Acad. Sci. 2002, 967, 43-51.

[21] Ceriello, A., Colagiuri, S, International Diabetes Federation guideline for management of postmeal glucose: a review of recommendations. Diabetic Med. 2008, 25, 1151-1156.

[22] Blaak, E.E., Antoine, J.M., Benton, D., Björck, I., Bozzetto, L. et al., Impact of postprandial glycaemia on health and prevention of disease. Obesity Rev. 2012, 13, 923-984.

[23] Jenkins, D.J., Wolever, T.M., Taylor, R.H., Barker, H., Fielden, H. et al., Glycemic index of foods: a physiological basis for carbohydrate exchange. Am. J. Clin. Nutr. 1981, 34, 362-366.

[24] Sadler, M, Food, Glycaemic Response and Health. International Life Sciences Institute (ILSI) Europe, Brussels, 2011.

[25] Venn, B.J., \& Green, T.J, Glycemic index and glycemic load: measurement issues and their effect on diet-disease relationships. Eur. J. Clin. Nutr.,2007, 61, S122-S131. 
[26] Livesey, G., Taylor, R., Hulshof, T., Howlett, J, Glycemic response and health—a systematic review and analysis: relations between dietary glycemic properties and health outcomes. Am. J. Clin. Nutr. 2008, 87, 258S-268S.

[27] Zhang, G., Hamaker, B.R, Slowly digestible starch: concept, mechanism, and proposed extended glycemic index. Crit. Rev. Food Sci. Nutr. 2009, 49, 852-867.

[28] Higgins, J.A, Resistant starch: metabolic effects and potential health benefits. J. AOAC Int. 2004, 87, 761-768.

[29] Butterworth, P.J., Warren, F.J., Grassby, T., Patel, H., \& Ellis, P.R, Analysis of starch amylolysis using plots for first-order kinetics. Carbohydrate Polymers, 2012, 87, 2189-2197.

[30] Edwards, C.H., Warren, F.J., Milligan, P. J., Butterworth, P.J., \& Ellis, P.R, A novel method for classifying starch digestion by modelling the amylolysis of plant foods using firstorder enzyme kinetic principles. Food Funct. 2014, DOI: 10.1039/c4fo00115j.

[31] Lehmann, U., Robin, F, Slowly digestible starch-its structure and health implications: a review. Trends Food Sci. Technol. 2007, 18, 346-355.

[32] Miao, M., Jiang, B., Cui, S.W., Zhang, T., Jin, Z, Slowly digestible starch - A review. Crit. Rev. Food Sci. Nutr, 2013, DOI:10.1080/10408398.2012.704434.

[33] Sajilata, M.G., Singhal, R.S., Kulkarni, P.R, Resistant starch—A review. Comp. Rev. Food Sci. Saf. 2006, 5, 1-17. 
[34] Liljeberg, H., Granfeldt, Y., Bjorck, I, Metabolic responses to starch in bread containing kernels versus milled flour. Eur. J. Clin. Nutr. 1992, 46, 561-575.

[35] Brand-Miller, J., McMillan-Price, J., Steinbeck, K, Caterson, I, Review article:

Carbohydrates - the good, the bad and wholegrain. Asia Pac. J. Clin. Nutr. 2008, 17 (S1), 1619.

[36] Sozer, N., Cicerelli, L., Heiniö, R.-L., Poutenan, K, Effect of wheat bran addition on in vitro starch digestibility, physico-mechanical and sensory properties of biscuits. J. Cereal Sci. 2014, 60, 105-113.

[37] Rai, K.N., Gowda, C.L.L., Reddy, B.V.S., Sehgal, S, Adaptation and potential uses of sorghum and pearl millet in alternative and health foods. Comp. Rev. Food Sci. Saf. 2008, 7, 340-352.

[38] Scazzina, F., Siebenhandl-Ehn, S., Pellegrini, N, The effect of dietary fibre on reducing the glycaemic index of bread. Brit. J. Nutr. 2013, 109, 1163-1174.

[39] Izydorczyk, M.S., Cenkowski, S., Dexter, J, Optimizing the bioactive potential of oat bran by processing. Cereal Foods World 2014, 59, 127-136.

[40] Fincher, G.B., Stone, B.A, in: Wrigley, C., Corke, H., Walker, C.E. (Eds.), Encyclopedia of Grain Science, vol. 1, Elsevier, Oxford, 2004, pp. 206-222. 
[41] Wood, P.J, Cereal $\beta$-glucans in diet and health. J. Cereal Sci. 2007, 46, 230-238.

[42] Cavallero, G.R., Empilli, S., Brighent, F., Stanca, A.M, High $(1 \rightarrow 3,1 \rightarrow 4)$ - $\beta$-glucan barley fractions in bread making and their effects on human glycemic response. J. Cereal Sci. 2002, 36, 59-66.

[43] Regand, A., Chowdhury, Z., Tosh, S.M., Wolever, T.M.S., Wood, P, The molecular weight, solubility and viscosity of oat beta-glucan affect human glycemic response by modifying starch digestibility. Food Chem. 2011, 129, 297-304.

[44] Lappi, J., Selinheimo, E., Schwab, U., Katina, K., Lehtinen P. et al., Sourdough fermentation of wholemeal wheat bread increases solubility of arabinoxylan and protein and decreases postprandial glucose and insulin responses. J. Cereal Sci. 2010, 51, 152-158.

[45] Beck, E.J., Tapsell, L.C., Batterham, M.J., Tosh, S.M., Huang, X.-F, Oat $\beta$-glucan supplementation does not enhance the effectiveness of an energy-restricted diet in overweight women. Brit. J. Nutr. 2010, 103, 1212-1222.

[46] Tosh, S.M, Review of human studies investigating the post-prandial blood-glucose lowering ability of oat and barley food products. Eur. J. Clin. Nutr. 2013, 67, 310-317.

[47] Van der Merwe, B., Erasmus, C., Taylor, J.R.N, African maize porridge: A food with slow in vitro starch digestibility. Food Chem. 2001, 72, 347-353. 
[48] Mahasukhonthachat, K., Sopade, P.A., Gidley, M.J, Kinetics of starch digestion as affected by particle size. J. Food Eng. 2010, 96, 18-28.

[49] Waniska, R.D., Rooney, L.W., McDonough, C.M, in. In: Wrigley, C., Corke, H., Walker, C.E. (Eds.), Encyclopedia of Grain Science, vol. 3, Elsevier, Oxford, 2004, pp. 127136.

[50] Grundas, S.T., Wrigley, C, in: Wrigley, C., Corke, H., Walker, C.E. (Eds.), Encyclopedia of Grain Science, vol. 3, Elsevier, Oxford, 2004, pp. 391-400.

[51] Al-Rabadi, G.J., Torley, P.J., Williams, B.A., Bryden, W.L., Gidley, M.J, Particle size heterogeneity in milled barley and sorghum grains: Effects on physico-chemical properties and starch digestibility. J. Cereal Sci. 2012, 56, 396-403.

[52] Rooney, L.W., Pflugfelder, R.L., Factors affecting starch digestibility with special emphasis on sorghum and corn. J. Anim. Sci. 1986, 63, 1607-1623.

[53] Wu, Y., Holding, D.R., Messing, J, $\gamma$-Zeins are essential for endosperm modification in quality protein maize. Proc. Natl. Acad. Sci. USA 2010, 107, 12810-12815.

[54] Correa, C.E.S., Shaver, R.D., Pereira, M.N. ,Lauer, J.D., Kohn, K, Relationship between corn vitreousness and ruminal in situ starch degradability. J. Dairy Sci. 2002, 85, 3008-3012. 
[55] Ezeogu, L.I., Duodu, K.G., Taylor, J.R.N, Effects of endosperm texture and cooking conditions on the in vitro starch digestibility of sorghum and maize flours. J. Cereal Sci. 2005, 42, 33-44.

[56] Zhang, G., Hamaker, B.R, Low $\alpha$-amylase digestibility of cooked sorghum flours and effect of protein. Cereal Chem. 1998, 75, 710-713.

[57] Ezeogu, L.I., Duodu, K.G., Emmambux, M.N., Taylor, J.R.N, Influence of cooking conditions on the protein matrix of sorghum and maize endosperm flours. Cereal Chem. 2008, 85, 397-402.

[58] Taylor, J.R.N., Emmambux, M.N, Developments in our understanding of sorghum polysaccharides and their health benefits. Cereal Chem. 2010, 87, 263-271.

[59] Chandrashekar, A., Kirleis, A.W, Influence of protein on starch gelatinization in sorghum. Cereal Chem. 1988, 65, 457-462.

[60] Butchi Lakshmi, K., Vimala, V, Hypoglycemic effects of selected sorghum recipes. Nutr. Res. 1996, 10, 1651-1658.

[61] Prasad, M.P.R., Rao, B.D., Kalpana, K., Rao, M.V., Patil, J.V, Glycaemic index and glycaemic load of sorghum products. J. Sci. Food Agric. 2014, DOI: 10.1002/jsfa/6861.

[62] Foster-Powell, K., Holt, S.H.A., Brand-Miller, J.C, International table of glycemic index and glycemic load values: 2002. Amer. J. Clin. Nutr. 2002, 76, 5-56. 
[63] Petitota, M., Abecassis, J., Micard, V, Structuring of pasta components during processing: impact on starch and protein digestibility and allergenicity. Trends Food Sci. Technol. 2009, 20, 521-532.

[64] Colonna, P., Barry, J.L., Cloarec, D., Bornet, F., Gouilloud, S. et al., Enzymic susceptibility of starch from pasta. J. Cereal Sci. 1990, 11, 59-70.

[65] Fardet, A., Hoebler, C., Baldwin, P.M., Bouchet, B., Gallant, D. J. et al., Involvement of the protein network in the in vitro degradation of starch from spaghetti and lasagne: a microscopic and enzymic study. J. Cereal Sci. 1998, 27, 133-145.

[66] Tester, R.F., Xi, Q., Karkalas, J, Review: Hydrolysis of native starches with amylases. Anim. Feed Sci. Technol. 2006, 130, 39-54.

[67] Naguleswaran, S., Jihong, L., Bressler, D., Hoover, R, Amylolysis of large and small granules of native triticale, wheat and corn starches using a mixture of $\alpha$-amylase and glucoamylase. Carbohyd. Poly. 2012, 88, 864-874.

[68] Naguleswaran, S., Vasanthan, T., Hoover, R., Bressler, D, The susceptibility of large and small granules of waxy, normal and high-amylose genotypes of barley and corn starches towards amylolysis at sub-gelatinization temperatures. Food Res. Int. 2013, 51, 771-782. 
[69] Kawagoe, Y. The characteristic polyhedral, sharp-edged shape of compound-type starch granules in rice endosperm is achieved via the septum-like structure of the amyloplast. $J$. Appl. Glycoscience 2103, 60, 29-36.

[70] Emmambux, M.N., Taylor, J.R.N, Morphology, physical, chemical and functional properties of starches from cereals, legumes and tubers cultivated in Africa: A review. Starch/Stärke 2013, 65, 715-729.

[71] Tester, R.F., Karkalas, J., Qi, X, Starch structure and digestibility enzyme-substrate relationship. W. Poultry Sci. J. 2004, 60, 186-195

[72] Behall, K.M., Scholfield, D.J., Yuhaniak, I., Canary, J, Diets containing high amylose vs amylopectin starch: effects on metabolic variables in human subjects. Am. J. Clin. Nutr. 1989, 49, 337-344.

[73] Hoebler, C., Karinthi, A., Chiron, H., Champ, M, Bioavailability of starch in bread rich in amylose: metabolic responses in healthy subjects and starch structure. Eur. J. Clin. Nutr. 1999, 53, 360-366.

[74] Zhu, L., Gu, M., Meng, X., Cheung, S.C.K., Yu, H. et al., High-amylose rice improves indices of animal health in normal and diabetic rats. Plant Biotech. J. 2012, 10, 353-362.

[75] Siwela, M., Taylor, J.R.N., De Milliano, W.A.J., Duodu, K.G, Occurrence and location of tannins in finger millet grain and antioxidant activity of different grain types. Cereal Chem. 2007, 84, 169-174. 
[76] Lemlioglu Austin, D., Turner, N.D., McDonough, C.M., Rooney, L.W, Effects of brans from specialty sorghums on in vitro starch digestibility of soft and hard sorghum endosperm porridges. Cereal Chem. 2012, 89, 190-197.

[77] Lemlioglu-Austin, D., Turner, N.D., McDonough, C.M., Rooney, L.W. Effects of sorghum [Sorghum bicolor (L.) Moench] crude extracts on starch digestibility, estimated glycemic index (EGI) and resistant starch (RS) contents of porridges. Molecules 2012, 17, 11124-11138.

[75] Mkandawire, N.L., Kaufman, R.C., Bean. S.R., Weller, C.L., Jackson, D.S, Effects of sorghum (Sorghum bicolor (L.) Moench) tannins on $\alpha$-amylase activity and in vitro digestibility of starch in raw and processed flours. J. Agric. Food Chem. 2012, 61, 44484454.

[79] Daiber, K.H, Enzyme inhibition by polyphenols of sorghum grain and malt. J. Sci. Food Agric. 1975, 26, 1399-1411.

[80] Hargrove, J. L., Greenspan, P., Hartle, D. K., \& Dowd, C. Inhibition of aromatase and $\alpha-$ amylase by flavonoids and proanthocyanidins from Sorghum bicolor bran extracts. J. Med. Food, 2011, 14, 799-807.

[81] Kim, J.-S., Hyun, T. K., \& Kim, M.-J. The inhibitory effects of ethanol extracts from sorghum, foxtail millet and proso millet on $\alpha$-glucosidase and $\alpha$-amylase activities. Food Chem. 2011, 124, 1647-1651. 
[82] Barros F, Awika, J.M., Rooney, L.W, Interaction of tannins and other sorghum phenolic compounds with starch and effects on in vitro starch digestibility. J. Agric. Food Chem. 2012, 60, 11609-11617.

[83] Eelderink, C., Moerdijk-Poortvliet, T.C.W., Wang, H., Schepers, M., Preston, T. et al., The glycemic response does not reflect the in vivo digestibility of fiber-rich wheat products in healthy men. J. Nutr. 2012, 142, 258-163.

[84] Kuma, V., Sinha, A.K., Makkar, H.P.S., Becker, K, Dietary roles of phytate and phytase in human nutrition: A review. Food Chem. 2101, 120, 945-959.

[85] Brinch-Pederson, H., Madsen, C.K., Holme, I.B., Dionisio, G, Review: Increased understanding of the cereal phytase complement for better mineral bio-availability and resource management. J. Cereal Sci. 2014, 59, 373-381.

[86] Yoon, J.H., Thomson, L.U., Jenkin, D.J.A, The effect of phytic acid on in vitro rate of starch digestibility and blood glucose response. Am. J. Clin. Nutr, 1983, 38, 835-842.

[87] Bornet, F.R., Fontvieille, A.M, Rizkalla S., Colonna, P. et al., Insulin and glycemic responses in healthy humans to native starches processed in different ways: correlation with in vitro alpha-amylase hydrolysis. Am. J. Clin. Nutr. 1989, 32, 315-23. 
[88] Singh, J., Dartois, A., Kaur, L, Starch digestibility in food matrix: a review. Trends Food Sci. Technol. 2010, 21, 168-180.

[89] Sagum, R., Arcot, J, Effect of domestic processing methods on the starch, non-starch polysaccharides and in vitro starch and protein digestibility of three varieties of rice with varying levels of amylose. Food Chem. 2000, 70, 107-111.

[90] Roopa, S., Premvalli, K.S, Effect of processing on starch fractions in different varieties of finger millet. Food Chem. 2008, 106, 875-882.

[91] Kim, J.C., Mullan, B.P., Hampson, D.J., Pluske, J.R, Effects of amylose content, autoclaving, parboiling, extrusion, and post-cooking treatments on resistant starch content of different rice cultivars. Aust. J. Agric. Res., 2006, 57, 1291-1296.

[92] Lee, K.Y., Lee, S., Lee, H.G, Influence of storage temperature and autoclaving cycles on slowly digestible and resistant starch (RS) formation from partially debranched rice starch. Starch/Stärke 2013, 65, 694-701.

[93] Vinoy, S., Normand, S., Meynier, A., Sothier, M.., Cereal processing influences postprandial glucose metabolism as well as the GI effect. J. Am. College Nut. 2013, 32, 7991.

[94] Garsetti, M., Vinoy S., Lang, V., Holt, S. et al., The glycemic and insulinemic index of plain sweet biscuits: relationships to in vitro starch digestibility. J. Am. College Nut. 2005, 24, 441-447. 
[95] Balance, S., Sahlstrom, S., Lea, P., Nagy, N. E. et al., Evaluation of gastric processing and duodenal digestion of starch in six cereal meals on the glycaemic response using an adult fasted dynamic gastric model. Eur. J. Nutr. 2013, 52, 799-812.

[96] Sánchez-Pardo, M.E., Ortiz-Moreno, A., Mora-Escobedo, R., Necoechea-Mondragón, H, In vitro starch digestibility and predicted glycemic index of microwave and conventionally baked pound cake. Plant Foods Hum. Nutr. 2007, 62, 99-105.

[97] Li, J., Han, W., Xu, J., Xiong, S., Zhao, S, Comparison of morphological changes and in vitro starch digestibility of rice cooked by microwave and conductive heating. Starch/Stärke, 2014, 66, 549-557.

[98] Slute, R, Hydrothermal modification of starches: the difference between annealing and heat/moisture- treatment. Starch/Stärke, 1992, 44, 205-214

[99] Chung, H.J., Cho, D.W., Park, J.D., Kweon, D.K., Lim S.T, In vitro starch digestibility and pasting properties of germinated brown rice after hydrothermal treatments. J. Cereal Sci. 2012, 56, 451-456.

[100] Amadou, I., Gounga, M. E., Shi., Y.H., Le, G.W, Fermentation and heat-moisture treatment changes on the physicochemical properties of foxtail millet (Setaria italica) flour. Food Bioprod. Process. 2014, 92, 38-45. 
[101] Rombo, G.O., Taylor, J.R.N., Minnaar, A, Effect of irradiation, with and without cooking of maize and kidney bean flours, on porridge viscosity and in vitro starch digestibility. J. Sci. Food Agric. 2001, 81, 497-502.

[102] Yoon, H.S., Yoo, J.Y., Kim, J.H., Lee J.W., Byun M.W. et al., In vitro digestibility of gamma-irradiated corn starches. Carbohydr. Polym. 2010, 81, 961-963.

[103] Rombo, G.O., Taylor, J.R.N., Minnaar, A, Irradiation of maize and bean flours: effects on starch physicochemical properties. J. Sci. Food Agric. 2004, 84, 350-356.

[104] Chavan, R.S., Chavan, S.R, Sourdough technology—a traditional way for wholesome foods: a review. Comp. Rev. Food Sci. Food Saf. 2011, 10, 169-182.

[105]. Taylor, J.R.N, in: Wrigley, C., Corke, H., Walker, C.E. (Eds.), Encyclopedia of Grain Science, vol. 1, Elsevier, Oxford, 2004, pp. 380-390.

[106] De Angelis, M., Damiano, N., Rizello, C.G., Cassone A. et al., Sourdough fermentation as a tool for the manufacture of low-glycemic index white bread enriched in dietary fibre. Eur. Food Res. Technol. 2009, 229, 593-601.

[107] Östman, E.M., Elmståhl, G.M.L., Björck, I.M E, Barley bread containing lactic acid improves glucose tolerance at a subsequent meal in healthy men and women. J. Nutr. 2002, 132, 1173-1175. 
[108] Östman, E.M., Nilsson, M, Liljeberg Elmståhl, H.G.M., Molin, M., Björck , M.E.,On the effect of lactic acid on blood glucose and insulin responses to cereal products: mechanistic studies in healthy subjects and in vitro. J. Cereal Sci. 2002, 36 339-346.

[109] Obiro, W C., Ray, S.S., Emmambux, M.N, V-amylose structural characteristics, methods of preparation, significance and potential applications. Food Rev. Int. 2012, 28, 412438.

[110] Wokadala, O.C., Ray, S.S., Emmambux, M.N, Occurrence of amylose-lipid complexes in teff and maize starch biphasic pastes. Carbohydr. Polym. 2012, 90, 655-660.

[111] Crowe, T.C., Seligman, S.A., Copeland, L, Inhibition of enzymatic digestion of amylose by free fatty acids in vitro contributes to resistant starch formation. J. Nutr. 2000, 130, 2006-2008.

[112] Rendón-Villalobos, R., Agama-Acevedo, E., Osorio-Diaz, P., Tovar, J., Bello-Pérez L. A, Proximal composition and in vitro starch digestibility in flaxseed-added corn tortilla. $J$. Sci. Food Agric. 2009, 89, 537-541.

[113] Fardet, A, New hypotheses for the health-protective mechanisms of whole-grain cereals: what is beyond dietary fibre? Nutr. Res. Rev. 2010, 23, 65-134.

[114] Poutanen, K, Past and future of cereal grains as food for health. Trends Food Sci. Technol. 2012, 25, 58-62. 
[115] Belobrajdic, D.P., Bird, A.R, The potential role of phytochemicals in wholegrain cereals for the prevention of type-2 diabetes. Nutr. J. 2013, 12:62.

[116] Taylor, J.R.N., Duodu, K.G, Effects of processing sorghum and millets on their phenolic phytochemicals and the implications of this to the health-enhancing properties of sorghum and millet food and beverage products. J. Sci. Food Agric. 2014, DOI 10.1002/jsfa.6713.

[117] Kim, J., Park, Y, Anti-diabetic effect of sorghum extract on hepatic gluconeogenesis of streptozotocin-induced diabetic rats. Nutr. Metab. 2012, 9, 1-7.

[118] Schakel, S.F., Van Heel, N., Harnack, J, in: Wrigley, C., Corke, H., Walker, C.E. (Eds.), Encyclopedia of Grain Science, vol. 3, Elsevier, Oxford, 2004, Appendix 1.

[119] Shin, H.S., Ingram, J.R., McGill, A.-T., Poppitt, S.D, Lipids, CHOs, proteins: Can all macronutrients put a "brake” on eating? Physiol. Behav. 2013, 120, 114-123.

[120] Shin, H.S., Poppitt, S.D., McGill, A.-T., Lo, K., Ingram, J, Foods for appetite control: Can carbohydrates stimulate the ileal brake and enhance satiety? Obesity Res. Clin. Pract. 2013, 7(S2), e23. 